特別講演 JIPE-34-13

\title{
Power Electronics in Utility Application in Korea
}

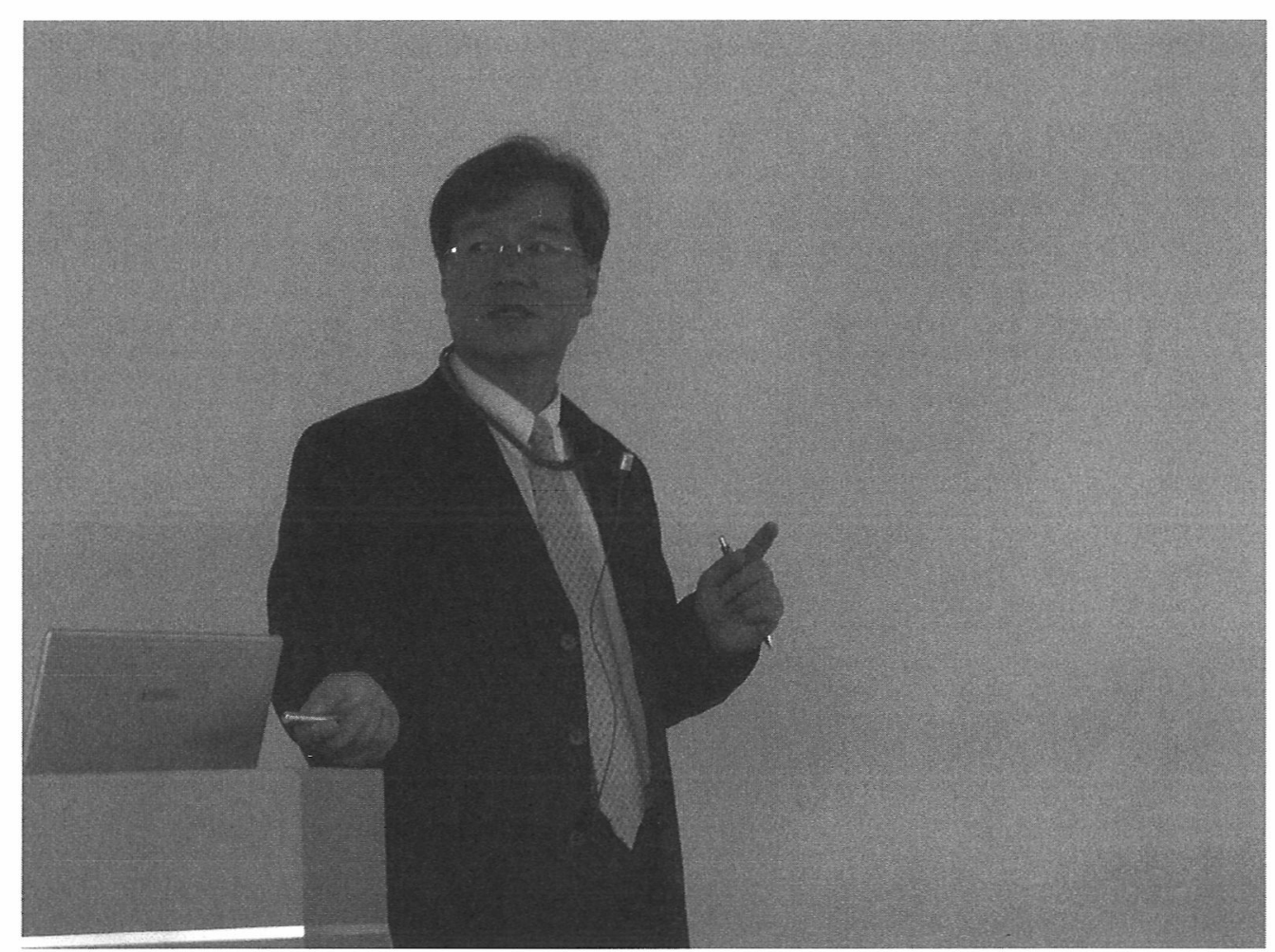

\author{
忠北大学 \\ Jaeho Choi
}

(Choi 先生には、平成 20 年 8 月 2 日、第 174 回定例研究会においてご講演頂きました) 

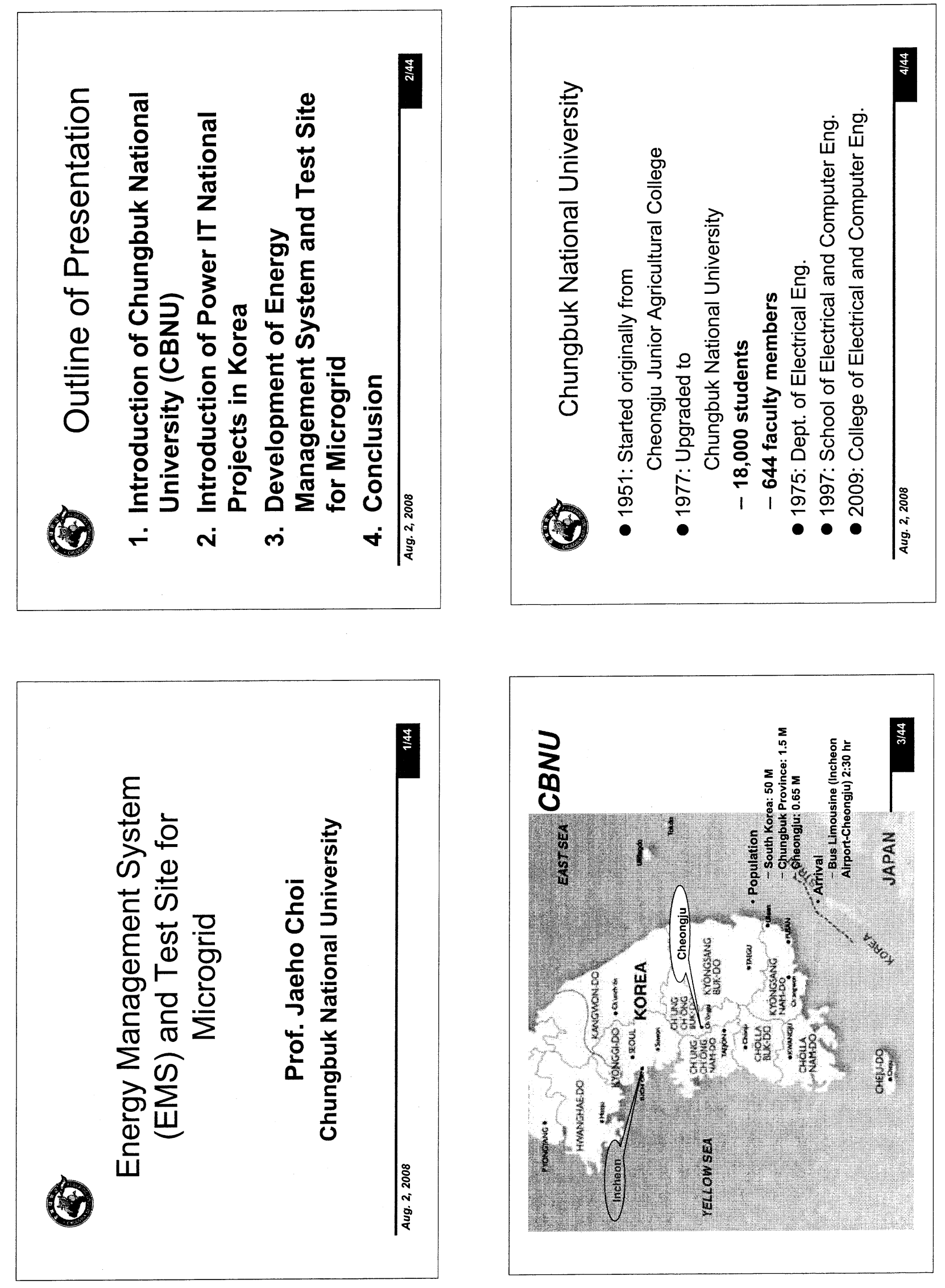

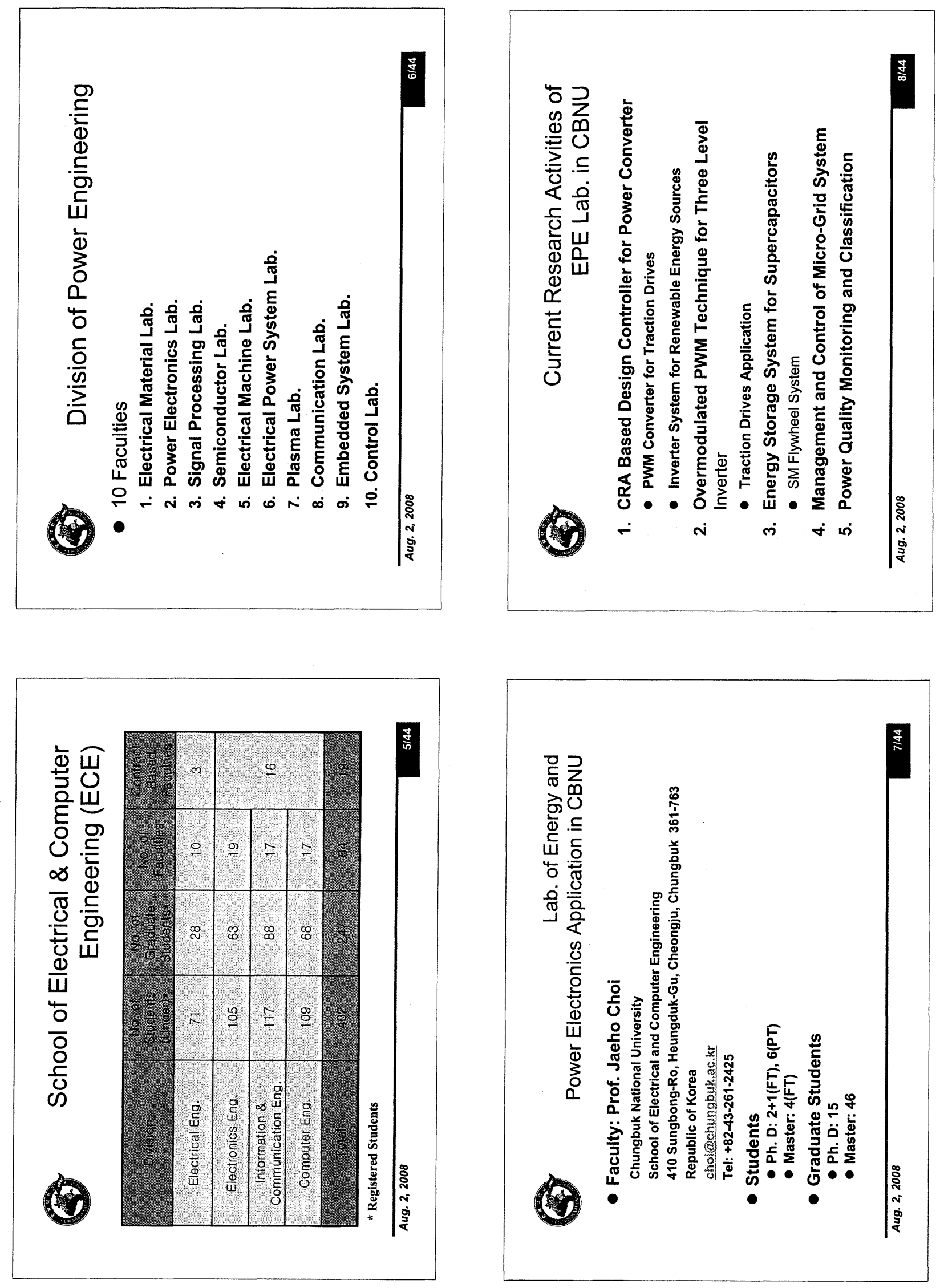

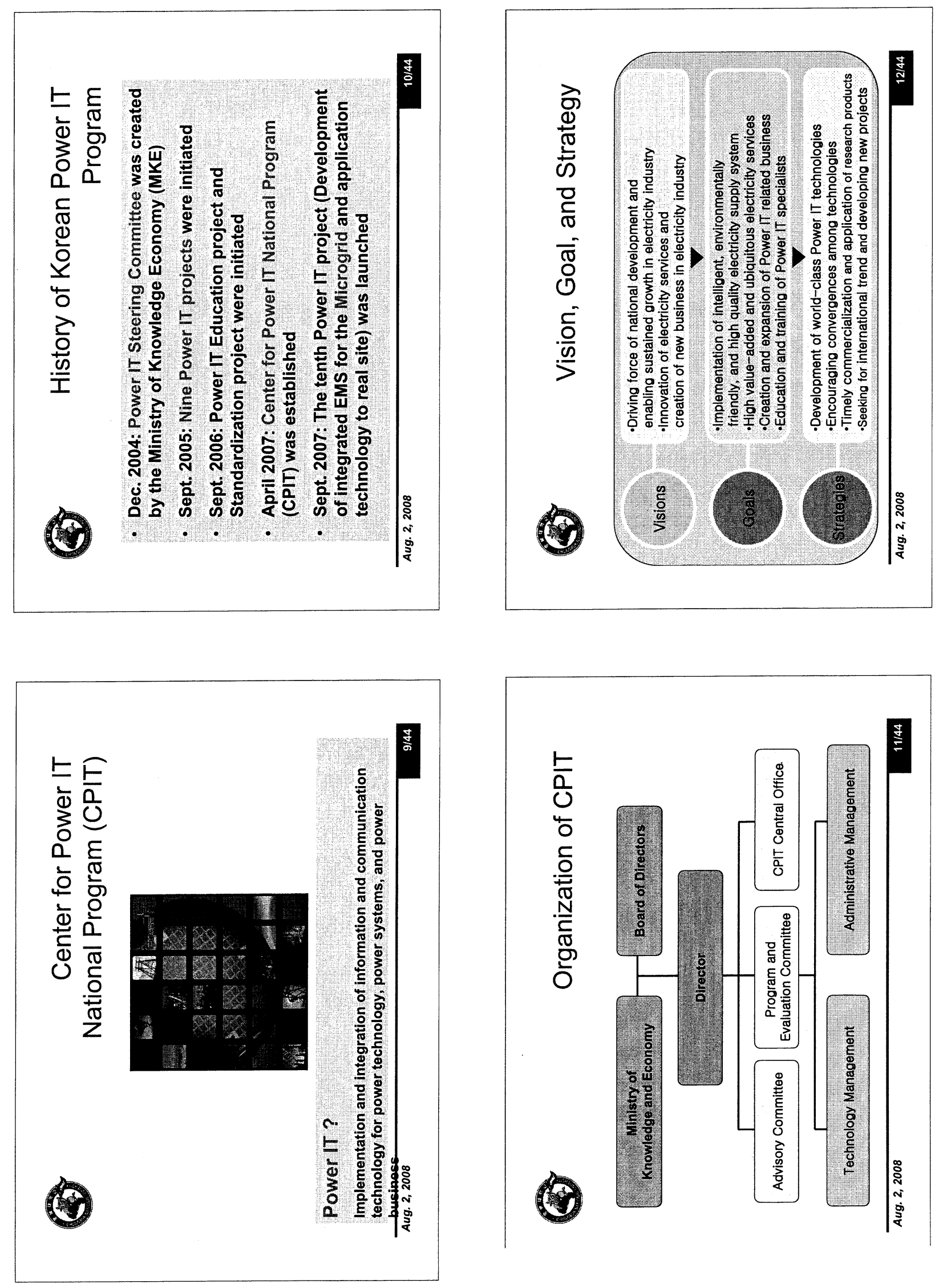

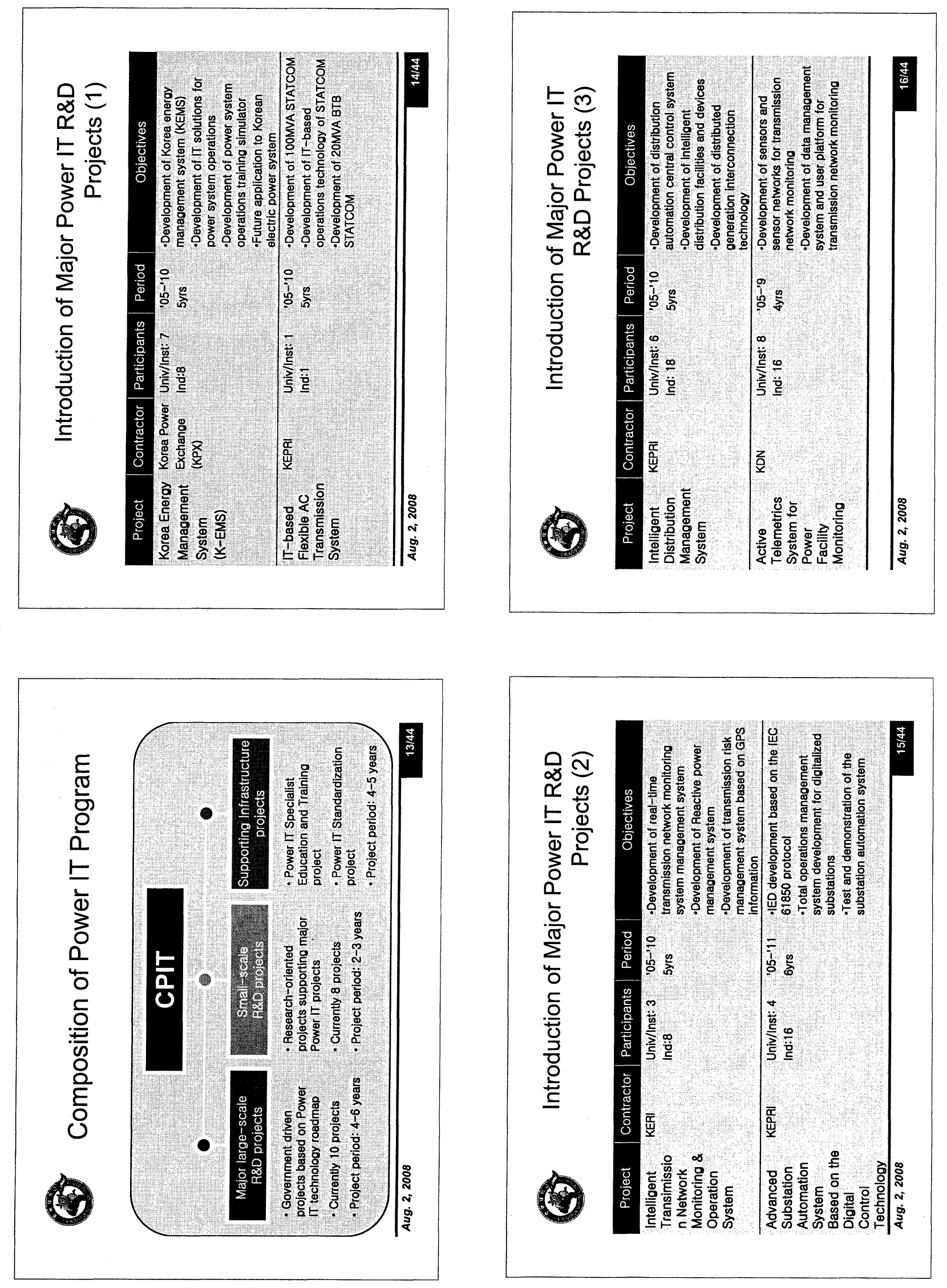

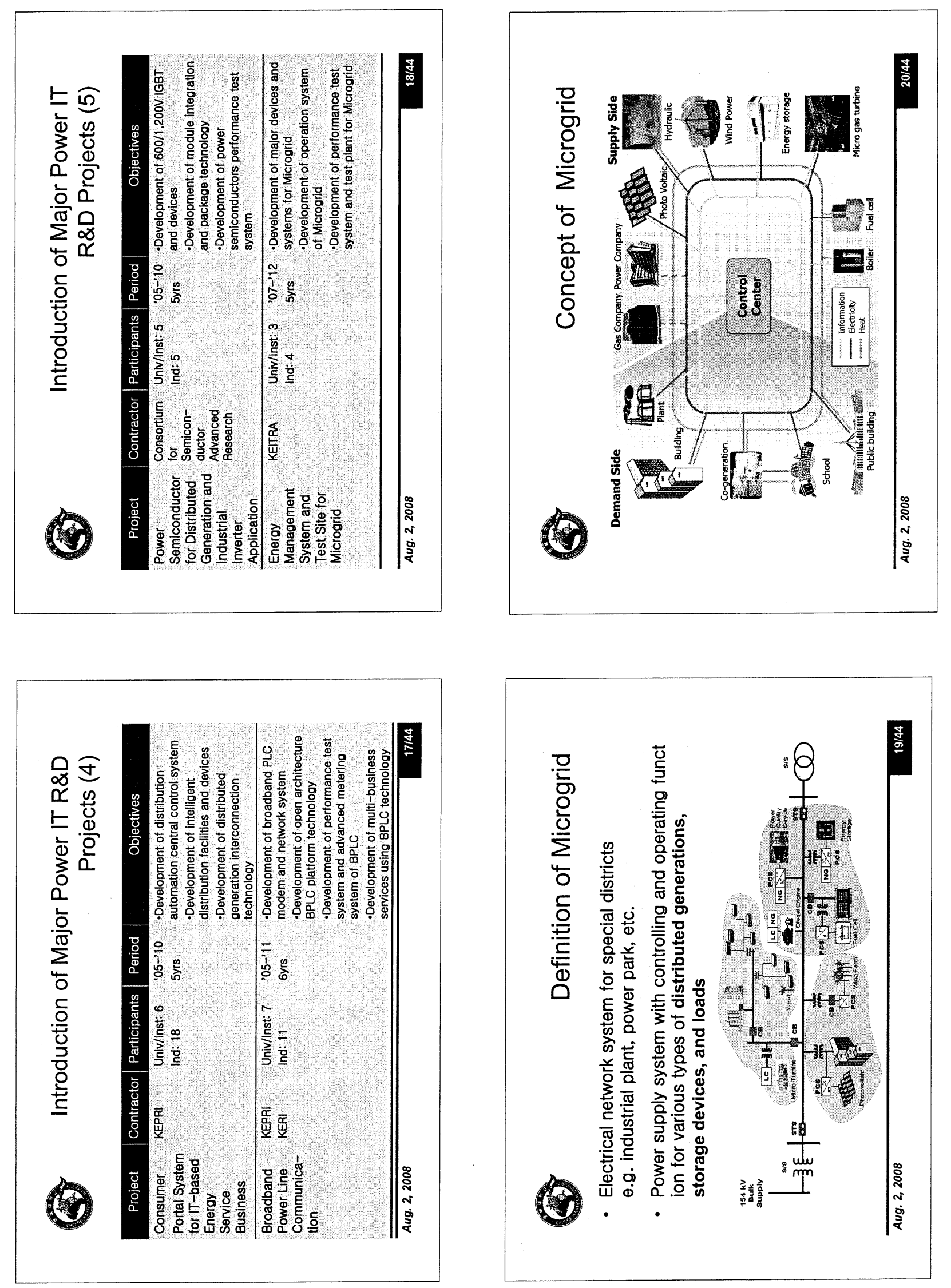

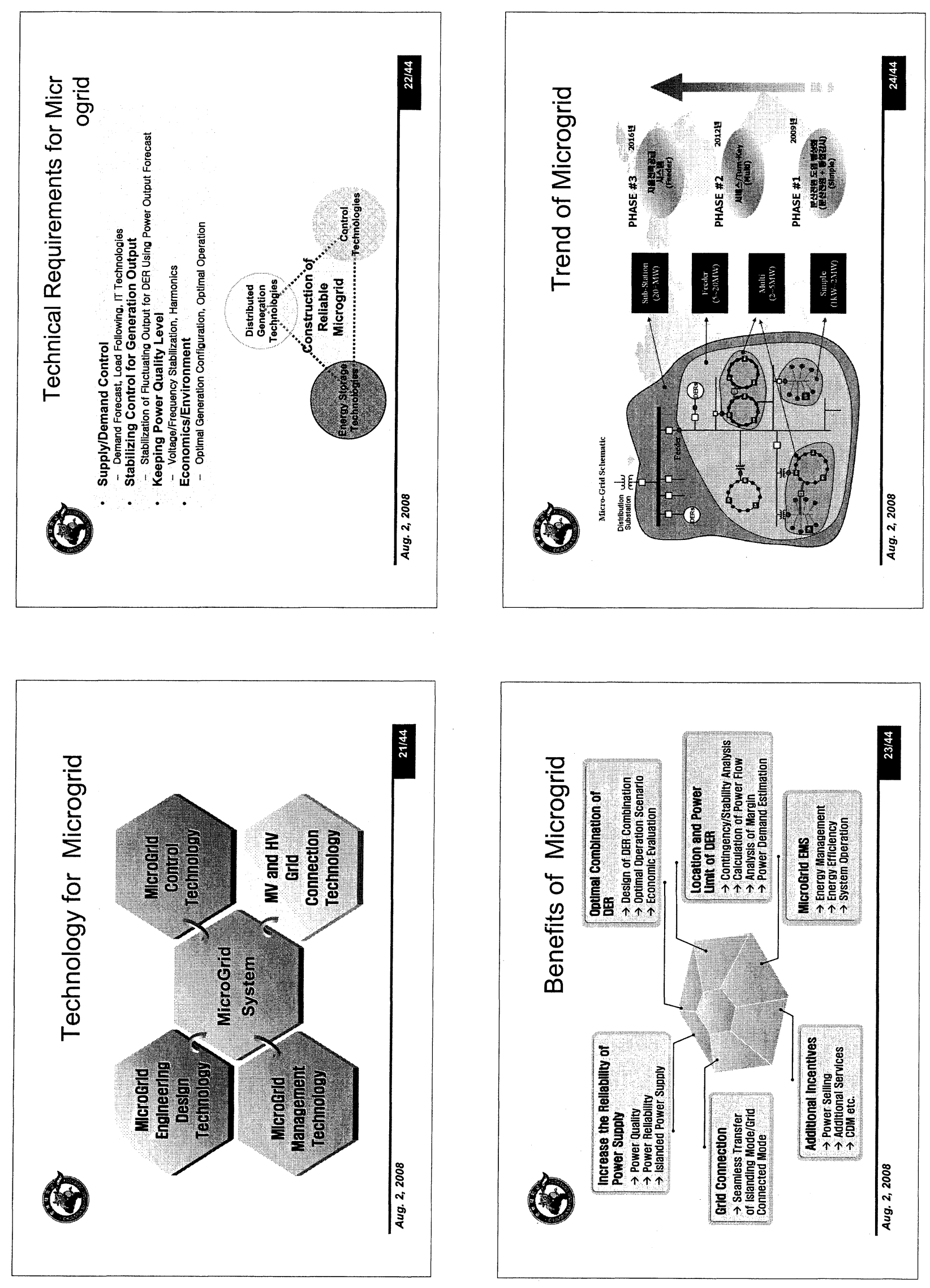

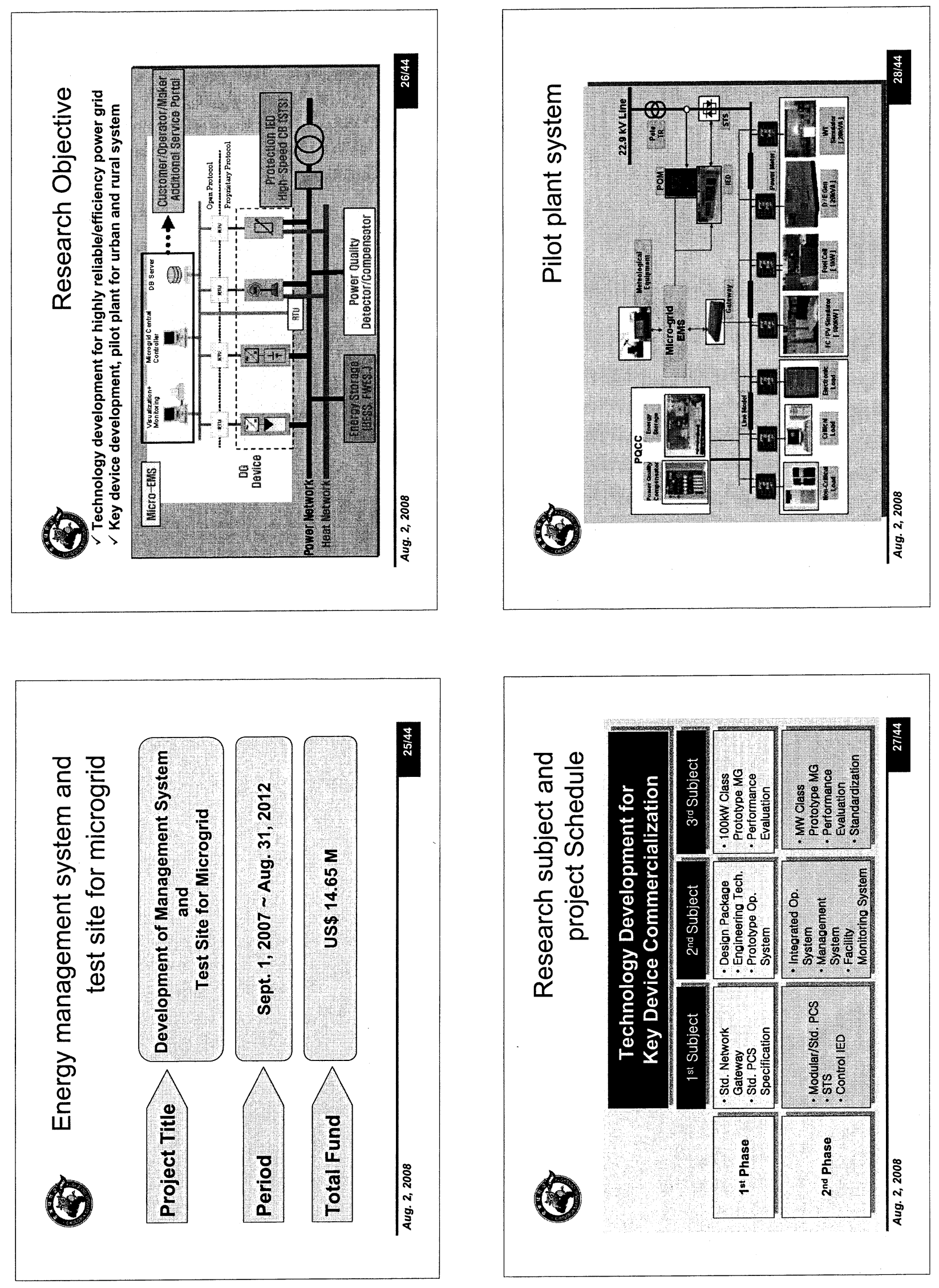

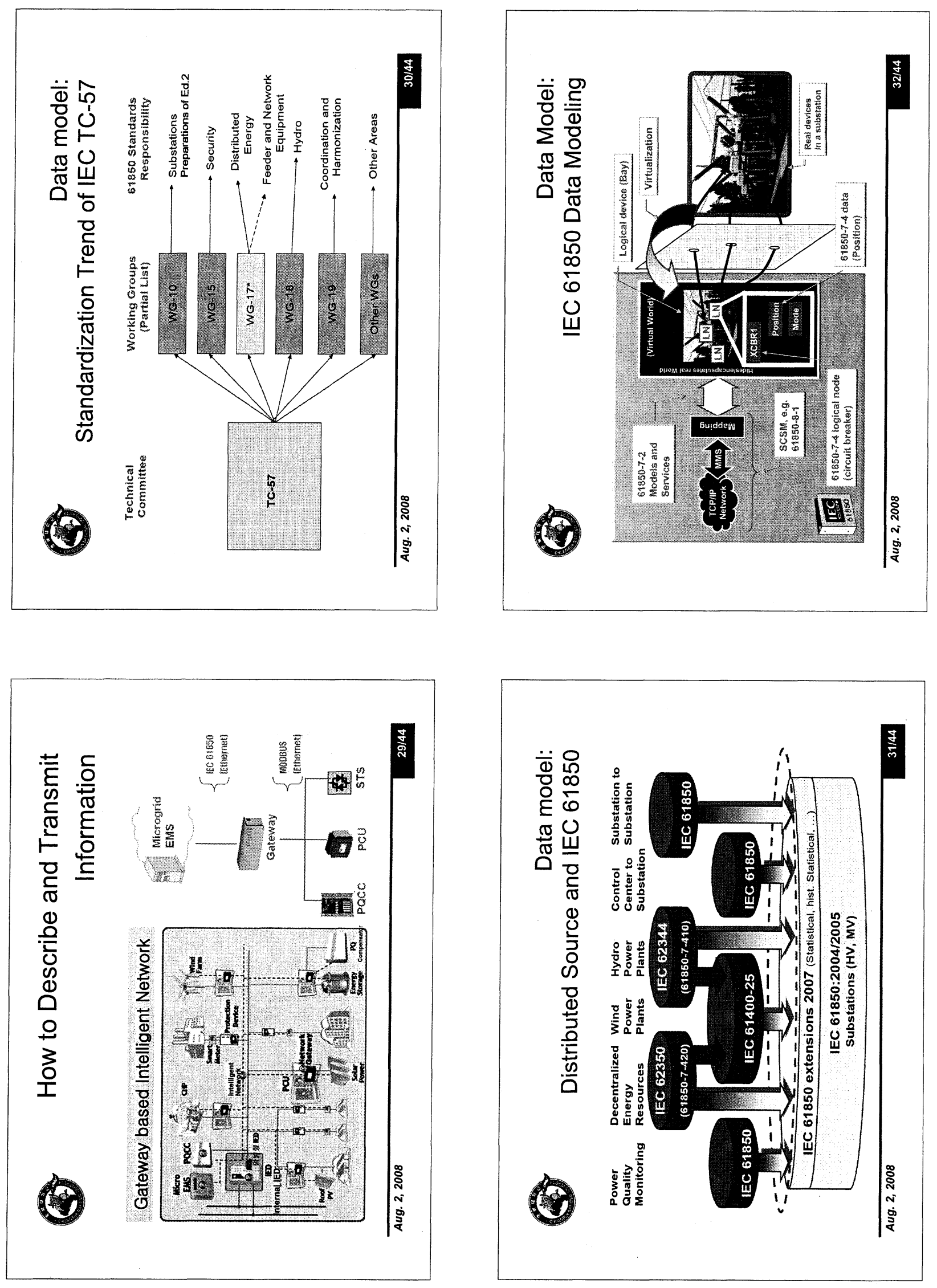

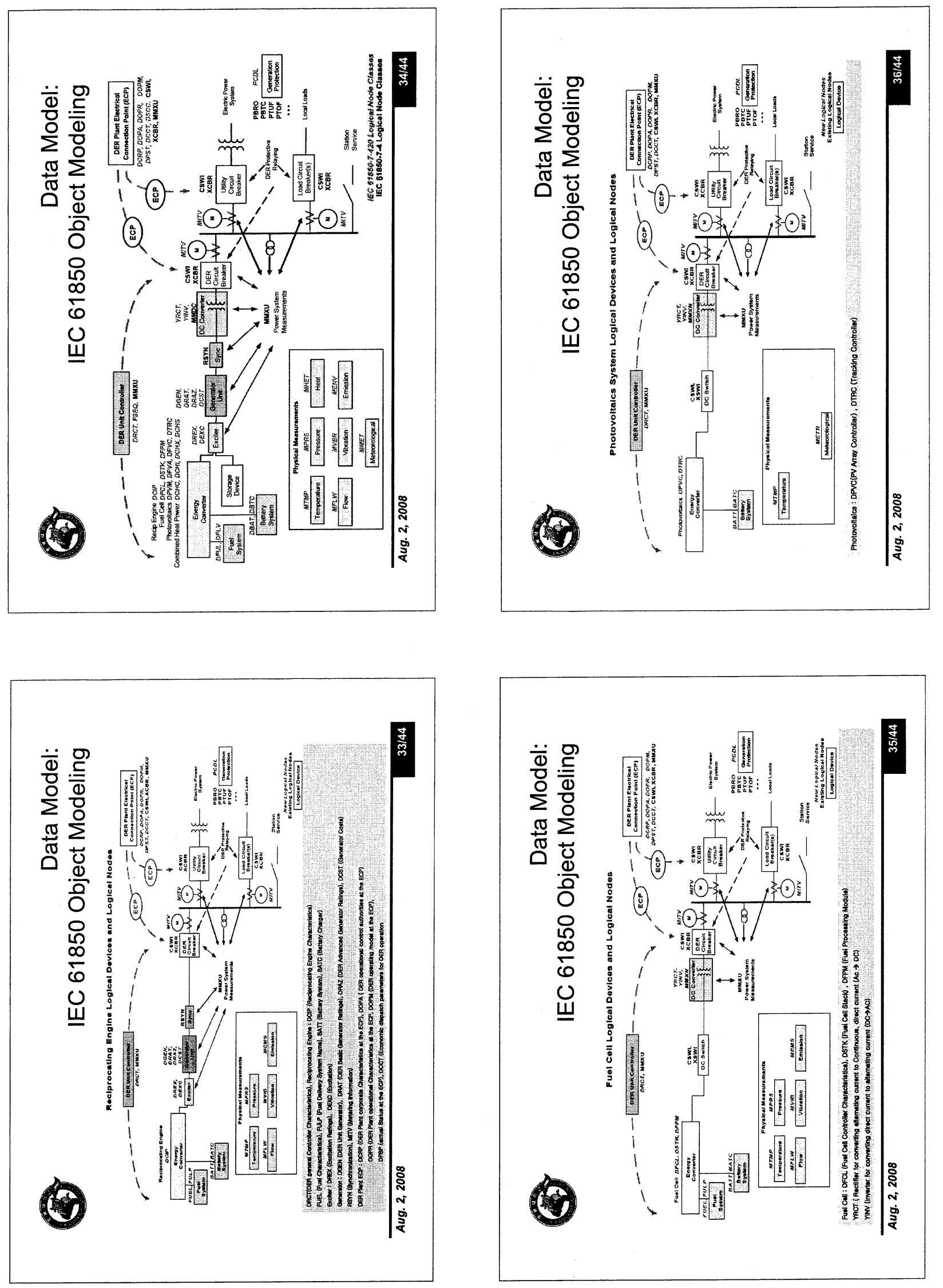

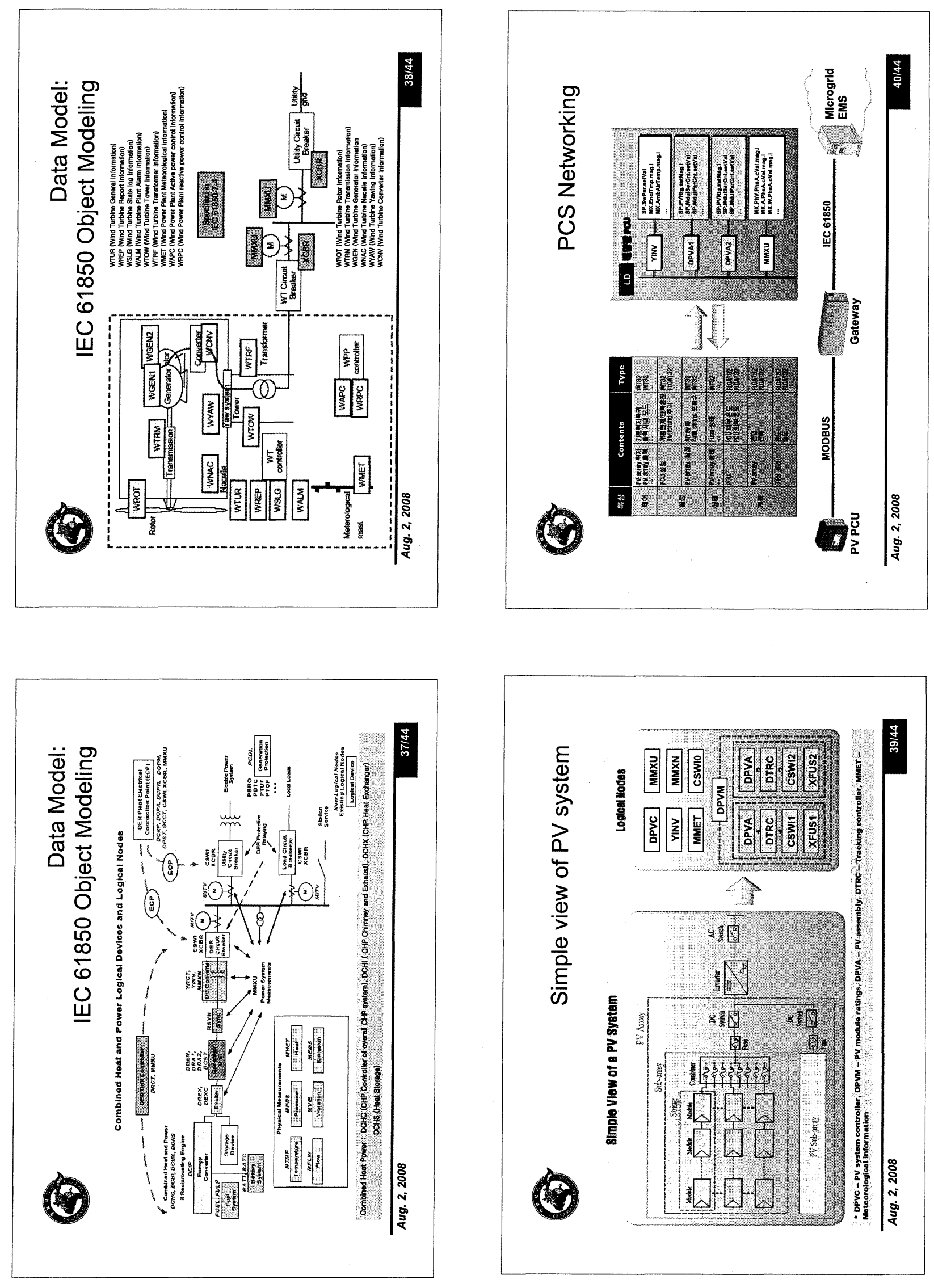

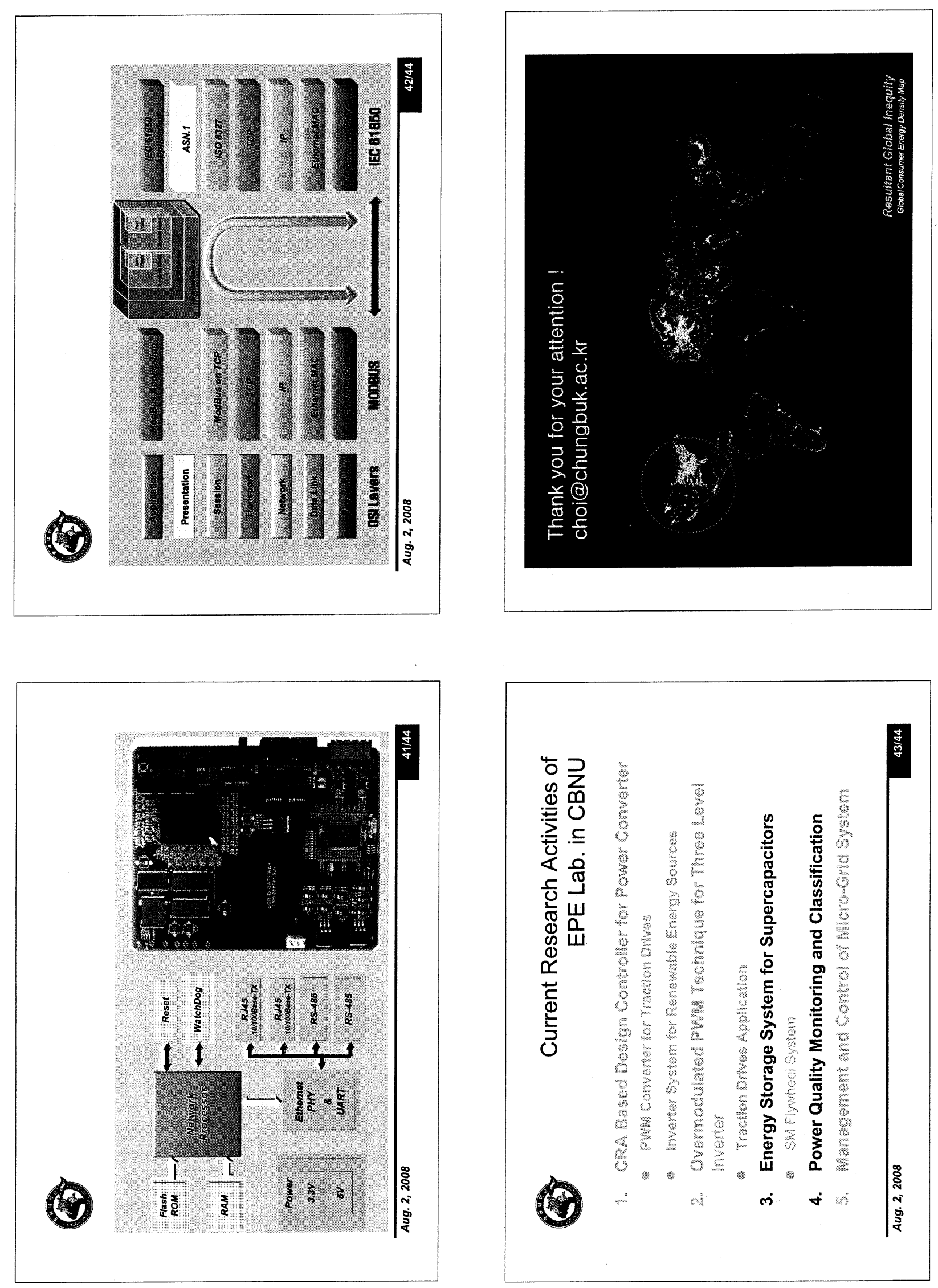